Evaluar.

$2005, n^{\circ} 5$ (octubre)
Laboratorio de Evaluación Psicológica y Educativa. Facultad de Psicología Universidad Nacional de Córdoba (Argentina).ISSN N ${ }^{\circ} 1515$ - 1867

77

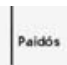

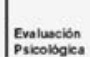

Edgardo Pérez / Josefina Passera

Fabián Olaz / María Osuna

Orientación, información

y educación para la elección de carrera

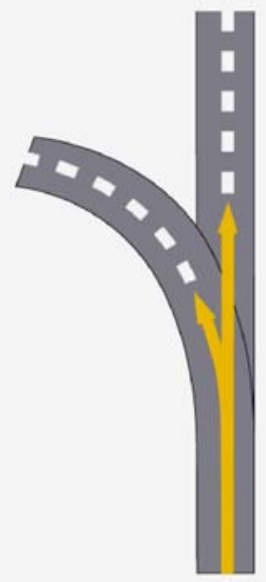

\title{
Orientación, Información y Educación para la elección de carrera
}

Por Edgardo Pérez, Josefina Pássera, Fabián Olaz \& María Osuna (2005). Buenos

Aires: Editorial Paidós

\section{Livio Grasso}

\section{Universidad Nacional de Córdoba}

Este libro ha sido elaborado por docentes de la Universidad Nacional de Córdoba, dedicados a tareas de enseñanza y también de investigación y desarrollo. Su lectura es una experiencia realmente placentera, por varias razones.

Una de ellas es el material presentado, que se centra alrededor de algunas ideas recientemente introducidas y de creciente vigencia en orientación: los conceptos de 
desarrollo de carrera, educación para la carrera y otros, provenientes de la teoría socialcognitiva de carrera, como los relativos a la autoeficacia. Se encuentran también bosquejos de interesantes teorías contemporáneas tales como la de Lent, Brown \& Hackett y la de los Cinco factores de Personalidad, así como de experiencias innovadoras como el pool internacional de ítems para evaluación de la personalidad. Se describen técnicas de intervención novedosas, instrumentos para identificar las necesidades específicas de cada orientado, la observación sistemática de puestos de trabajo y los sistemas de orientación e información computarizados, entre otras.

Una segunda razón es la orientación general del texto. Al respecto cabe destacar: el enfoque preventivo y psicopedagógico que prevalece en el planteo de la obra y al que se dedican específicamente dos capítulos, la continua referencia a resultados de la investigación y a teorías con apoyo empírico y capacidad predictiva establecidas para respaldar las afirmaciones, las abundantes referencias a estudios e instrumentos desarrollados en nuestro medio; el oportuno señalamiento de cuestiones que en nuestro país demandan hoy la atención de profesionales e investigadores; la inclusión de una sección sobre temas prioritarios en la investigación internacional.

En mi opinión, se trata de una obra realmente interesante tanto para el estudiante que se introduce en el tema como para el profesional del área que busca actualización. Los profesionales e investigadores de otras áreas encontrarán en este texto ideas inspiradores y, asimismo, disfrutarán de su lectura, pues está escrito de manera fluida y amena.

Evaluar.

2005, $\mathbf{n}^{\circ} 5$ (octubre) 